University of Wollongong

Research Online

Faculty of Informatics - Papers (Archive)

Faculty of Engineering and Information

Sciences

9-7-2007

\title{
Beyond Mere Compliance of RFID Regulations by the Farming Community: A Case Study of the Cochrane Dairy Farm
}

\author{
A. Trevarthen \\ University of Wollongong \\ Katina Michael \\ University of Wollongong, katina@uow.edu.au
}

Follow this and additional works at: https://ro.uow.edu.au/infopapers

Part of the Physical Sciences and Mathematics Commons

\section{Recommended Citation}

Trevarthen, A. and Michael, Katina: Beyond Mere Compliance of RFID Regulations by the Farming Community: A Case Study of the Cochrane Dairy Farm 2007.

https://ro.uow.edu.au/infopapers/558 


\title{
Beyond Mere Compliance of RFID Regulations by the Farming Community: A Case Study of the Cochrane Dairy Farm
}

\author{
Abstract \\ Radio-frequency identification (RFID) is changing the face of livestock identification and management. \\ Beyond satisfying the regulations of government agencies for livestock to be a part of a national \\ identification system for tracking purposes, farmers are now considering venturing beyond mere basic \\ compliance systems. Once installed, farmers have begun to realize that their initial capital investment into \\ an RFID system holds great strategic potential. The initial outlay while substantial is a once only cost that \\ with a few more application-centric uses can yield a return on investment manifold. This paper presents a \\ case study of the Cochrane Dairy Farm situated on the New South Wales South Coast. The case study \\ shows that the Cochrane Dairy farm utilizes advanced total farm management techniques that will before \\ too long lead to greater dividends. The contribution of this paper is in presenting how a dairy farm has \\ adopted RFID initially to meet government directives, and then for broader more personalized \\ requirements. Farming processes are defined explicitly and the paper points to encourage other farmers \\ to consider adoption of RFID beyond the need for compliance and toward the perspective of longer term \\ productivity and strategic visibility.

\section{Keywords} \\ RFID, national livestock identification system, tags, dairy farmers, regulation, compliance, traceability, \\ case study

\section{Disciplines} \\ Physical Sciences and Mathematics

\section{Publication Details} \\ This paper was originally published as Trevarthen, A and Michael, $\mathrm{K}$, Beyond Mere Compliance of RFID \\ Regulations by the Farming Community: A Case Study of the Cochrane Dairy Farm, The Sixth International \\ Conference on Mobile Business, Toronto, Canada, 9-11 July, 1-8.
}




\title{
Beyond Mere Compliance of RFID Regulations by the Farming Community: A Case Study of the Cochrane Dairy Farm
}

\author{
Adam Trevarthen, Katina Michael \\ School of Information Systems and Technology, University of Wollongong \\ ATrevarthen@hotmail.com,katina@uow.edu.au
}

\begin{abstract}
Radio-frequency identification (RFID) is changing the face of livestock identification and management. Beyond satisfying the regulations of government agencies for livestock to be a part of a national identification system for tracking purposes, farmers are now considering venturing beyond mere basic compliance systems. Once installed, farmers have begun to realize that their initial capital investment into an RFID system holds great strategic potential. The initial outlay while substantial is a once only cost that with a few more application-centric uses can yield a return on investment manifold. This paper presents a case study of the Cochrane Dairy Farm situated on the New South Wales South Coast. The case study shows that the Cochrane Dairy farm utilizes advanced total farm management techniques that will before too long lead to greater dividends. The contribution of this paper is in presenting how a dairy farm has adopted RFID initially to meet government directives, and then for broader more personalized requirements. Farming processes are defined explicitly and the paper points to encourage other farmers to consider adoption of RFID beyond the need for compliance and toward the perspective of longer term productivity and strategic visibility.
\end{abstract}

\section{Introduction}

This case study was undertaken on the Cochrane dairy farm, located in Pyree on the New South Wales South Coast. This farm has been selected as the case study, as it has a substantial use of radio frequency identification (RFID) technology, and is well-known in the region as one of the most advanced RFID setups. As the farm also utilizes RFID tags that are compliant with Australia's NLIS (National Livestock Identification System), the farm provides an applicable example of how participants in this system can derive additional benefits through the use of RFID on their dairy farms.

\section{Previous literature}

Articles by Ishmael [1] and Karnjanatwe [2] provide a glimpse of the possibilities for utilizing electronic identification for enhanced farm management, however these articles are not focused upon the dairy farm industry, nor do they provide an in-depth look at the total farm management operations used at these farms. Ishmael (2001) tells of the economic benefits achieved by a group of farmers resulting from the utilization of RFID technology to provide individual identification and subsequently enhanced farm management operations on their beef farm in America. Karnjanatwe (2005) provides an insight into an actual application of RFID technologies used to enable enhanced farm management of pigs, such as automating the feeding process and regulating how much each pig eats. Geers et al. [3] do likewise, devoting a chapter to the electronic identification of farm animals, however this chapter does not have a dairy industry focus. Geers et al. demonstrate the growing awareness and importance of electronic identification for farm management. Considering improved disease and fraud controls, combined with the desirable and dominant cost-benefit ratio that can be derived from the utilization of electronic identification for farm management, Geers et al. (pp. 26-28) provide a clear message that electronic identification is the likely path of animal identification in the future. Michael's unpublished thesis [4] further supports this view. A section (pp. 249-250) regarding animal identification using RFID demonstrates that traditional forms of animal identification are considered inferior in comparison to RFID technology. James [5] and Davies [6] provide more information on deriving benefits specifically related to the dairy industry, however also lack depth and explanations of the farm management practices undertaken to gain these benefits. James states how electronic 
identification can be used to reduce the labor required for the milking process, providing large cost savings, while Davies demonstrates the ability to improve the quality of milk yields through controlled feeding processes based on electronic identification.

\section{The case study- the Cochrane Dairy}

The Cochrane dairy is a family-run business, operated by partners Geoff and Cathy Cochrane, their children, and one farm hand. The farm's core business function is dairy, however they have recently diversified, and begun experimenting with rearing steers until they are 2 or 3 years old. The Pyree farm is one of several properties in the region owned by the Cochranes'. Established on approximately 360 acres, the Pyree farm supports around 350 head of lactating Illawarra cattle (their full herd size is approximately 420 including the dry cows they have on their other properties). All cows in the herd have a National Livestock Identification System (NLIS) compliant RFID tag attached to their right ear. This tag is applied to calves immediately (0-4 days) after birth, and plays an integral role in the total farm management operations of this farm.

\subsection{The cows and the tags}

This RFID tag is utilized to aid in farm management operations from early in a cows' life. For a new born calf these tags are first utilized merely weeks after birth, as they provide the identification mechanism to enable automated calf feeding. Later in the cows' life (when they enter lactation), the RFID tags are also utilized in the dairy to identify each cow as she walks into the milking parlor. This identification subsequently facilitates a number of functions within the dairy. As each cow exits the dairy, these tags are also utilized to facilitate the use of automatic drafting gates.

Exhibit 1 shows a separate plastic identification tag is also placed in the cow's right ear (traditional tag), which displays the cows on farm identification number (as opposed to the RFID tag number). This number is allocated by the Cochranes' at the time of a cow's birth, and used to identify the cow in relation to their own herd. These tags provide farmers with an important immediate visual identification mechanism for each cow. It is traditionally one of the most common forms of identifying cows on farms that are not utilizing RFID. Additionally, the Cochranes' are maintaining the use of these tags in order to comply with NLIS regulations, which state that farmers must maintain the use of either a tail or ear tag as a secondary identification mechanism until the 1 st of January 2006 [7].

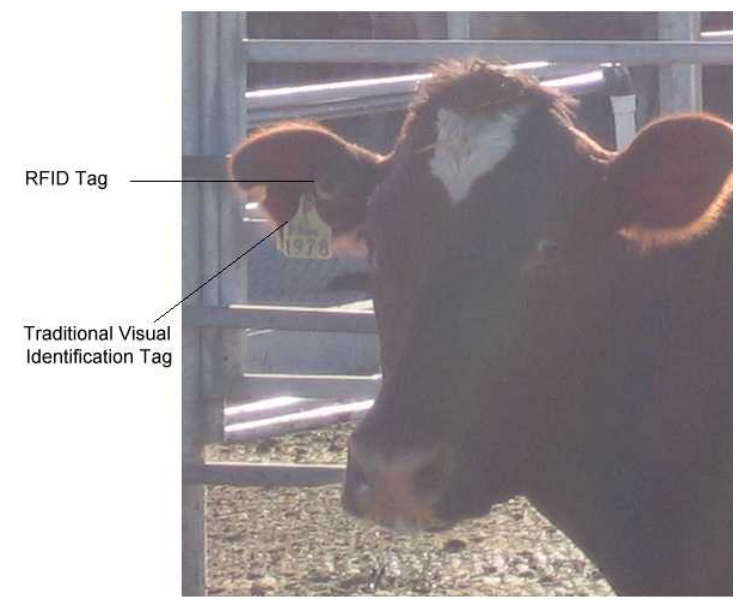

Exhibit 1. NLIS RFID Tag on Livestock

\subsection{Herd management software}

The software application adopted by the Cochranes' is Dairy 2000, and is produced by Victorian company OnFarm Electronics. As with most implementations, Dairy 2000 has been specifically tailored to suite the data storage and herd management needs of the dairy industry, and provides the ability to store information pertaining to each individual cow in the Cochrane herd.

\subsection{The dairy}

The current dairy was built approximately two years ago, and features a twenty-five a-side Herringbone milking parlor ( 25 bails on each side, therefore catering for up to 50 cows at once). The dairy features a high degree of automation, some of which is combined with RFID technology, while others are triggered by manual actions. The dairy contains the following features: an RFID reader upon entry to the milking parlor; an automated entry gate opening and closing; feed bins above bails; feed troughs for each milking bail; a rotating bail entry blockers; two LCD computer screens (displaying cow information); an audio speaker (to provide audio notification of particular cow attributes); a set of milking cups for each milking bail; milking controller units for each set of milking cups; automated raising of the feed trough to allow cows to exit milking parlor; RFID reader upon exit to the dairy; drafting gates associated with RFID reader upon exit to dairy; and multiple high pressure hoses throughout.

\subsection{Milking times and operators}

Milking takes place twice daily on this farm firstly, at 5am, and secondly at 3pm. Each milking session takes approximately two hours, and is conducted by two operators. 


\section{Milking procedure}

The milking procedure of the Cochrane dairy is one major area gaining benefits from the use of RFID. A detailed examination of this procedure grants insight into how RFID is currently being utilized.

Dairy preparation: Prior to milking, one operator prepares the dairy for milking. This involves ensuring the equipment is clean and ready, and that the computer system is ready for operation.

Move fresh calves to be with their mother: Fresh calves (new born calves) require their mother's milk for the first few days of their lives. The Cochranes' facilitate this by moving the fresh cows into a pen with their natural mother. The calves can then suckle their mother for milk while the milking in the dairy is conducted.

Round-up cattle - Move cattle to dairy holding area: While the cows are approaching the dairy, both operators spend time observing the herd for any signs of cows that may be on heat. If the operators determine a cow to be on heat, they will record her identification number (from the visual identification tag placed in her ear beside the RFID tag). If this cow is determined to be beyond their first 60 days of lactation, the operators will then record this cow number into the nearby computer and select it to be drafted when it exits the dairy (where the cow will then be artificially inseminated). After the cows reach the holding area, both operators finalize the preparations for milking. The gate to the holding area is then closed by an operator (ensuring the cows to be milked are retained in the holding area), before re-entering the dairy, ready for milking to begin.

Operator presses button - opens milking parlor entry gate: Operator presses button to open the milking parlor entry gate - gates open automatically.

Cows enter milking parlor - pass through RFID reader: Cows enter the milking parlor in single file, passing through a permanent RFID reader installed on the entry gates. This reader retrieves the identification number from the RFID tags attached to the ear of each cow. This unique identification number is then used to gather data pertaining to each cow from the central database.

Individual cattle information displayed on computer screen - audio readout to alert milkers of cattle requiring particular attention: As each cow passes through the RFID reader, their individual information is displayed on the two computer screens located in the dairy. These screens provide a selection of information pertaining to each cow. This information is drawn from the central herd management database, and the user is able to specify the specific fields of information to be displayed on the screen. The cows are listed in rows, with their characteristics displayed in the corresponding columns.

Cows with attributes requiring particular attention from the operators are highlighted with various colors on the computer screen. For example, slow milking cows are highlighted in red on the computer screen, cows that have freshly calved are highlighted in yellow etc. For these cows, an audio readout is also generated from the computer system, providing a verbal signal to aid in identifying cows requiring particular attention. This allows the operators to better plan their milking approach for a batch of cows, and aids to ensure they take the required actions. For example, the operators will begin to milk the slow milking cows before the others, thus aiding in efficiency for each batch of cows.

For freshly calved cows, and cows that have had a penicillin injection, the operator will also attach the milking cups to a separate holding drum. This effectively separates specific cow's milk from the main milk, allowing it to be thrown away after milking.

Cows enter bails in consecutive order: Cows enter their bails in sequential order (from one to twenty-five). The order in which they enter bails is enforced by having each bail blocked when the cows first enter. The only bail available for entry is the end bail (number 1). When a cow enters this bail, it will push forward a rotating bar. This will subsequently rotate and open the next bail (bail number 2). Enforcing this sequencing process allows the computer to establish which bail number each cow will enter as they are read.

When bails full, entry gate closed: By reading each cows' RFID tag as she enters the dairy, the computer system is able to determine when twenty-five cows have moved into the dairy. Thus, when a side is full, the entry gate automatically closes. This prevents other cows from entering the milking parlor during milking.

Rationed feed automatically dropped into individual bail troughs: Approximately 40 seconds after the cows have passed through the reader (enough time for them to reach their bail); the feed is automatically dispensed from feed holders above the bails. The amount of feed given to each cow varies according to her production and lactation cycle. 
Roughly, a cow producing 50 liters or more per milking session (extremely high) will receive 12 kilograms of feed. Those producing approximately 30 liters will receive 8 kilograms, 20 liters will receive 6 kilograms, and finally, those producing 12 liters or less per milking will be provided 2 kilograms of feed during the milking session. Production amounts in between these boundaries will receive an amount of feed rationed to their exact production.

Once a cow has passed their 150th day of their 300 day lactation cycle, they are considered to have past their peak production abilities. As such, the feed provided is then gradually decreased to only $75 \%$ of the figures provided above. As a cow passes the 250th day of lactation, they are considered to be well past their peak production capacity, and the feed is again gradually decreased to $50 \%$ of the above provided figures, so as to gradually wean the cow off this food supply. This $50 \%$ of the original stated amount is then maintained until the cow is dry and thus does not return to the dairy.

The data regarding how much milk each cow is producing is extracted from the central herd management database (this data is recorded by Dairy Express herd recording services) according to the cow's unique RFID identification number. This rationing of feed ensures that cows are provided the nutrients they require to continue their milk production.

When a cow enters the dairy for the first milking of her new lactation cycle, the automatic feeder also starts this cow at a low amount of feed (approximately 1 kilogram). The amount of feed is then gradually increased over a 20 day period, up to a standard 8 kilograms of feed. This feed is then maintained until the cows production capacity is measured (through the use of Dairy Express herd recording), and her amount of feed is then determined by this figure. This gradual incrementing of feed is required so as to allow time for the cow to develop the required bacteria in their stomachs to handle the wheat and grain in the feed.

Operators take any special actions that may be required: As the cows enter their bails, operators are able to take any required action on cows. For example, if a cow has had a penicillin injection in the last few days, their milk must be disposed of, as it is not suitable for consumption by any animal. Other actions that may be required include attaching the milk pipes for specific cows to a secondary milk vat. This vat is used to store milk that the Cochranes' consider second grade milk, and is later used to feed the calves via the automatic calf milking machine. Therefore, to maximize the quality of the milk provided to the manufacturer (in this case Dairy Farmers), the Cochranes' separate the lower quality milk. Thus, this separation and use of secondary milk maximizes the use of produced milk and provides enhanced benefits for the farmer.

Operators attach cups to teats - milking automatically begins: Operator presses lever to begin milking pulsation and suction within milking cups before attaching these cups to the teats of a cow. For slow milking cows, the operator will often begin the milking process by hand, so as to get the milk flowing. For the majority of cows, the cups are simply attached to all four teats however, some cows may have problems with a specific teat on their udder, may have had one teat dried off for a particular reason, or are currently being treated for a disease in a teat. Cows requiring these varied actions are identified by colored leg bands that are attached to the legs of cows using Velcro straps. The color and placement of the leg band signifies the position of the problem teat on this cow, and how the milking operator should conduct milking for her. It is up to the operators to recognize these leg bands and combinations, and to not apply milking cups to the teat identified as having the problem. Cows that have had a penicillin injection are identified with a single leg band (utilizing the color and placement code previously described to identify the problem teat), as well as blue spray paint on the back part of their udder.

Operators tend to any issues that may arise: Occasionally unpredictable events will occur that will require the operator's attention. These events include cows kicking the milking cups off before they have finished milking, cups not retracting correctly when milking completed, slow milkers may require a check to ensure they have provided all of their milk (requiring a manual feel of the milk left in the teat). The milk line filter is then placed in the milk line between the milking cups and the main milk flow line that leads to the milk storage vat. As milking is being conducted, milk flows through this filter before it enters the main milk flow line, thus aiding to remove any impurities in the milk. Additionally, as this filter is associated with each individual milking bail, this filter is a good indicator of the milk quality being provided by the cow in that milking bail.

Milking completes - cups fall from teat: The milking cups automatically detect when the cow has finished giving milk. As they fall from the teat a piece of cord linking the milking cups to the base of the milking controller unit will retract, thus raising the cups to a 
stationary position - keeping them off the floor and at a position ready for attachment on the next cow.

Operators spray disinfectant onto teats: As cows finish milking, operators spray an iodine-based disinfectant onto cow teats.

Operators spray homeopathy onto udders of specially marked cattle: While the process of spraying disinfectant onto teats is being conducted, homeopathy is also applied to the udders of those cows identified as requiring the treatment.

Clean equipment if ill cow just used: If a cow with an illness has just been milked, the operators clean the inside of the milking cups that were used on that cow.

Operator presses button, feed troughs lift to release cattle: When all cows in the row have completed milking, all additional actions taken, the operator is free to release the row of cows. This is achieved by pressing the designated release button. Pressing this button triggers the feeding bails that are currently placed in front of the cows to automatically be brought backward and raised into the air. This enables the cows to move out of their bails in a forward direction, underneath the feed bails. Once they have moved far enough out of their bails, the operator presses the lower button to bring the feeding bails back to the feeding position and ready to hold the next group of cows.

Cattle exit dairy at own will - pass through drafting gates upon exit: Once they have moved beyond the bails, cows may exit the dairy at their own will. As the cows are not occupying the bails, the operators can immediately bring in the next group of cows for milking into that row, thus aiding to save time and effort for the operators. As the cows exit the dairy, they again move single-file through a drafting gate.

RFID readers linked to drafting gates identify individual cows: An RFID reader is placed slightly in front of these drafting gates to determine the identity of each cow before they enter the gates. This reader attains the unique identification number from each cow's RFID tag, and utilizes this number to query the database and derives information relating to the direction in which the current cow should be directed.

Drafting gates react to individual cows - move to direct cow to holding paddock or back to grazing paddock: From the information gathered on each cow, the drafting gates will move to direct the cow to the desired area. By default, these gates point straight ahead to the grazing paddock but if a cow has been selected to be drafted out of the main group, then the drafting gates will move to direct a cow either to small holding paddocks on the left or right. When a cow that has been selected for drafting is recognized by the RFID reader, two flipper gates will rotate to block entry to the drafting gate for this cow. This gate prevents the selected cow from entering the drafting gate section until it has completely changed direction, and is ready to lead the selected cow directly to their designated paddock. Visual detection devices are utilized on the entry to the drafting gates to ensure that the cow that was read previous to the currently selected cow is clear of these gates before they close.

Repeat process until all cows milked: This completes the milking process for a batch of cows (one row of 25 cows). This process is then repeated for the remainder of the herd (approximately 300 cows), and is conducted on both sides of the milking parlor (enabling the dairy to cater for 50 cows at once). Each row of the dairy can be at a different stage of this process, thus aiding to maximize efficiency in milking - i.e. on one side of the dairy the operators may begin attaching milking cups to the cows, while the cows on the other side are moving in or out of their bails (where human intervention is not required).

Clean dairy: Once all cows in the herd have been milked and moved out of the dairy, the cleaning process begins. This involves thoroughly washing out the dairy floor and milking area, flushing out the faeces catcher, and hosing down any other areas that may have been dirtied, including the outside of the milking cups. Automatic cleaning of the milking equipment is then undertaken. To facilitate this, the milking operators place each set of milking cups onto their holding rack (four fixed prongs). A milking operator can then exit the milking parlor, and select on the central milking controlling computer to begin the cleaning cycle for the dairy equipment. This cleaning process involves pumping a range of chemicals (including alkaline and acid) throughout all pipes and milking equipment through which milk flows. The milking operators can then exit the dairy, and leave the cleaning process to manage itself.

Move secondary milk to calf feeder: The milk that was pumped to the secondary vat (milk taken from cows considered to be giving secondary quality milk) is then transported from the dairy to the calf feeding area. 
Take required action on drafted cattle: Once the dairy has been cleaned, the required action is then taken on the drafted cattle before releasing them to return to the grazing paddock with the rest of the herd.

\section{Automatic calf feeder}

The other key area in which RFID is utilized on the Cochrane farm is for the important process of calf feeding. To undertake this task, the Cochranes' have implemented an automatic calf feeder. This feeder utilizes a calves' RFID tag to gain their unique RFID identification number and regulate the amount of milk being provided to each calf on a daily basis. The automatic calf feeder dispenses milk through an artificial teat, which the calves suckle to gain the milk. Calves access this teat by walking into an entry gate (barrier) that ensures only one calf has access to the teat at any one time. As they approach the teat through this walkway, an RFID reader built in to the walkway gains the identification number of the calf from the RFID tag in its right ear. This number is then used to retrieve data regarding the amount of milk this calf is allowed to drink over a 24-hour period, and how much of this they have consumed already. If they have already drunk their full quota of milk over the past 24 hours, no milk will be supplied to the fake teat. This ensures that calves do not drink excessive amounts of milk. However, if they have not drunk their full quota, they will be provided with more milk until they reach this full quota. The calf feeder at the Cochrane dairy provides two separate milking points for feeding, thus enabling two calves to be fed at once. When the calf is first introduced to the calf feeder (from around 4-7 days after birth - before which they feed from their mother), they are provided 4 liters a day. As they grow older, they are gradually allowed more, up to a maximum of 7 liters. After approximately three months on the calf feeder, the calves will join the rest of the cows in the grazing paddocks, where they will not receive this supply. The calf feeder allows the farmers to view the amount of milk that any specific calf is drinking through a simple screen attached to the machine. This feature is highly useful, and the operators frequently utilize this to check that calves are drinking most, if not all of their allocated amount of milk.

To introduce a new calf to the feeding machine, the operator simply sets the mode on the calf feeder to record new calf. They then swipe the RFID identification tag passed the RFID reader in the feeder entry, and that calf is immediately registered.

\section{Herd information storage and retrieval}

The Cochrane dairy utilizes the Dairy 2000 software application to assist in their herd management operations. This software has the ability to store data on a range of characteristics for each cow, such as the date of artificial insemination, date calved (date a cow gave birth to a calf), treatments (such a penicillin), milking rates etc., as well as a range of data that may assist in facilitating herd management. As such, this software is able to provide an entire history of any particular cow. This data can be easily accessed and updated based on a cow's unique RFID tag number, or also by the cow's unique farm number as assigned by the Cochrane farm. This software application is the underlying component of all of the RFID operations of the dairy. The data contained in this program is accessed by the RFID readers and utilized to facilitate the relevant automation operations, such as deciding on the amount of feed to be provided to a cow etc. It also provides the interface to display individual cow data to the milking operators in the dairy during milking.

The Cochranes' also utilize 2 manual entry books as a form of running diary for their herd management operations - one for the purposes of recording cow information, and the second for recording paddock information. They fill in the cow diary with information pertaining to any actions taken on cows for that day. For example, penicillin injections, artificial inseminations etc. They manually write down the cow number, action taken and any other relevant information in this book. Retaining this form of manual record keeping subsequently requires the farmers to record cow data twice - once in the diaries, and again to transfer this information into the herd management software. This approach is required however, so as to enable the farmers to record information while they are in the field conducting the actions. Additionally, having this information provided in two forms and in two locations (the computer system located at the dairy and also the portable diary) provides valuable backup sources for this information.

The Cochranes' also utilize the services of Dairy Express herd recording to test the milk produced by each of their cows. The Cochranes' also download the results of this analysis, and are able to import this information directly into their herd management software. This allows for the information relating to each cow to be updated on a frequent monthly basis, thus aiding to provide up-to-date information to be utilized in RFID operations, and providing a common ground for analysis and comparisons to be made. 


\section{RFID benefits}

The Cochranes' believe that they are certainly gaining a good return on their RFID investment, both financially and in general convenience.

\subsection{Automatic feeding}

One of the benefits of the RFID setup is that it makes individual feeding uncomplicated. Having the computer calculate and deliver the appropriate amount of feed for each cow (depending on their production as measured during the last herd recording), makes the feeding process far easier for the operators, as it relieves them from managing this aspect of the milking process. Providing this automated feeding also guarantees that cows are provided the required amount of feed to sustain the amount of milk they are currently producing. Subsequently, this ensures that the cows are given the best chance at good health, while leaving no room for human error in providing the varied amounts. This approach also saves the farm significant money, as they do not have to provide large amount of feed for low producing cows, nor do they suffer from wasted feed through spilling. With feed accounting for a large proportion of dairy farm costs, it is certainly beneficial to ensure that this feed is being utilized to gain the best possible return. The ability to automatically detect recently calved cows (those new to the dairy for this lactation cycle), and to gradually introduce them to the feed is also a valuable asset. This ensures the cows do not fall victim to wheat or grain poisoning, as may happen if they immediately are provided with a large amount of feed. Thus, this provides another avenue to aid in the ensuring the health of cows, which subsequently aids to encourage high milk production and continued good health for the farms most important assets.

\subsection{Automatic drafting}

Another significant benefit is obviously the ability to automatically separate cows that require particular attention from the rest of the herd. This is achieved through the use of the RFID reader linked with the automatic drafting gates. By entering the numbers of the cattle to be drafted into the herd management software, these cows will be automatically separated from the rest of the herd at the designated milking session. This saves the farmers from having to attempt to identify individual cows outside of the milking session, and also saves them from having to exit the milking parlor and retrieve a cow as she exits the milking parlor if they wish to gain her at that time. As such, this automatic drafting can be seen to provide a reduction in hassle for the farmers, while increasing the efficiency of the milking process. The Cochranes' also utilize this drafting ability to provide additional attention for their selected show cows. By drafting their show cows to a separate paddock after each milking session, the Cochranes' are able to easily provide these cows with additional feed of hay and silage.

\subsection{Automatic calf feeder}

Automating the practice of calf feeding provides large benefits for the Cochranes', primarily through the reduction of labor required to undertake this activity. Prior to the automated calf feeder, the Cochranes' undertook calf feeding in the same manner as many other dairy farms - by grouping calves into age groups, and manually providing milk to each group of calves via buckets at designated feeding times. While effective, this approach is quite time consuming for the farmers, and depending on the manner in which the calves are fed, it may be difficult to gauge exactly how much milk each calf is receiving. Utilizing the automatic calf feeder, this human labor requirement is reduced, as the calf feeder will automatically manage the task. This results in the only remaining labor required for calf feeding being a regular check of the machine to ensure it is working correctly, and for the farmers to view the amount of milk each calf is currently consuming (easily achieved via the associated information screen for the machine). Of course the calves will require human attention for a number of other activities, however this large labor requirement for feeding is now virtually eliminated. This provides additional valuable time to the farmers to undertake other activities on the farm. Alternatively, the Cochranes' have elected to increase the amount of calves being raised on the dairy, without having to increase the amount of labor provided. The ability of the calf feeder to adjust the amount of milk being provided to each calf ensures that each calf receives the correct amount of milk required for their age on a daily basis. This aids to ensure that calves develop and grow healthily, while providing them with the ability to drink when they desire, rather than at a preset feeding time. As the calf feeder is capable of determining each calves' age (and subsequently the amount of milk to provide) through their identification tag, the machine also removes the requirement to group calves into similar age groups. As such, this further removes the labor requirement and hassle for farmers. This also benefits the calves, as they are free to associate and learn from a larger and more diverse group of other calves. 


\subsection{Provision of information during the milking procedure}

As noted earlier, selected information relating to each individual cow, as well as the bail number that each cow is assigned to in each milking row is displayed on two screens located at either end of the milking parlor. The ability for the milking operators to be provided with this information as the cows enter the milking parlor is highly useful for the Cochranes'. Primarily, this ability provides another mechanism for informing milking operators of any cows with particular characteristics that may subsequently require particular attention or additional steps to taken during the milking process. The associated audio readout of this information, as well as the color-coded highlighting of this cow on the computer screens also aids to ensure that these characteristics are recognized by the operators and appropriate action taken.

This relay of information also enables the operators to better plan their milking procedure for each row of cows that enter. This is possible as milking operators may begin preparations for milking of cows requiring particular attention as soon as they enter the milking parlor - as opposed to only recognizing that a cow requires additional actions to be taken when the operator arrives at this cow to place the milking cups on her. Additionally, the operators can also begin milking the slow milking cows first. Taking these actions aids to increase the efficiency of milking for each row of cows, subsequently aiding to reduce the total time taken for milking the herd.

\section{RFID cost-benefit}

The cost, as well as the effort and labor required to implement the current RFID setup on the Cochrane dairy certainly required a large investment of both time and money. The combined cost of both the hardware and software for the upgrade to RFID was estimated to be $\$ 60,000$. As to whether the Cochranes' believe this large investment has been justified, Tom Cochrane (2005) states, "the advantages have outweighed the cost of it, long term. Like, if you're talking only over a year, there's no way you can justify that cost, but if you justify it over 20 years, it's paid for itself well and truly." Regarding the ongoing costs of RFID, the Cochranes' do not see these are being excessive either. The main ongoing cost for this implementation is for additional RFID tags. However, as these tags are now mandated by law in NSW (due to NSW NLIS regulations), the Cochranes' point out that there is now no option but to identify cows with RFID devices anyway. As such, this cost cannot be attributed solely to ongoing costs of this setup, but is a required cost by law. Rather, the application of these tags at the start of a cows' life (rather than only as they exit the farm) and subsequent use of these tags to facilitate farm management operations is simply an optional way for the farm to gain benefits from this required cost.

\section{Future RFID implementation}

The Cochranes' have found great benefits from their use of RFID currently, and are interested in further advancing their RFID operations in the future. However, the only advancement that they are realistically considering is the implementation of milking meters for every milking bail. Implementing these milking meters will provide the ability to record the amount of milk each cow has provided at every milking session. This is in contrast to the current practice of only gaining these figures once a month through the use of the herd recording services of Dairy Express. Attaining milk production figures for every cow from every milking session will provide vastly more information for the farmers to utilize in their farm management decisions. This ability may facilitate enhancements to a range of other activities also, such as enabling more up-to-date figures to be utilized for the calculation of feed requirements for each cow. Further, this frequent recording of information may also serve as a means to detect problems with cows. All in all it is very important to remember that while RFID can aid in enhanced total farm management practices, it is the fundamental process that needs to be developed alongside the technology. The Cochrane Dairy Farm is a good example of alignment between the process and the technology, which has made it a successful case study for RFID adoption beyond that of compliance.

\section{References}

[1] Ishmael, W. 2001, The Power of One. Available http://beef-mag.com/mag/beef_power_one/

[2] Karnjanatwe, K. 2005, How RFID tags can track livestock, Bangkok Post. www.bangkokpost.com

[3] Geers, R., Puers, B., Goedseels, V. \& Wouters, P. 1997, Electronic Identification, Monitoring and Tracking of Animals, CAB International, New York. [4] Michael, K. 2003, The Automatic Identification Industry Trajectory, Thesis, Wollongong University. [5] James, D. 2004, 'Automatic cow identification pays in the milking parlour', Farmer's Weekly, p. 42.

[6] Davies, R. 1997, Electronic Gains Aplenty. http://www.agricultural-technology.co.uk/fwedit/

[7] NSW Department of Primary Industries Agriculture. 2004, NLIS. http://www.agric.nsw.gov. $\mathrm{au} /$ reader/nlis/questions-answers-nlis-nsw.htm 